\title{
Interveninig Swine Flu Epidemic
}

\author{
Saima Asif ${ }^{1 *}$, Tanweer Alam ${ }^{1,2}$ and Safila Naveed ${ }^{1}$ \\ ${ }^{1}$ Faculty of Pharmacy, Jinnah University for Women, Pakistan \\ ${ }^{2}$ Drug Regulatory Authority Government of Pakistan, Pakistan
}

\begin{abstract}
Since the emergence of Swine flu as global pandemic in 2009 thousands of cases have been reported worldwide with an alarming wave in Pakistan as well. The disease may prove to be deadlier in upcoming years. Despite availability of Vaccination and anti-viral therapy-appropriate preventive measures are seemed to be the only way out. A critical role could be played in this regards by Pharmacists to assist the patients about the viral disease, potential risks, clinical presentation, and course of the disease can help in early detection, isolation and treatment to prevent further spread of the disease. Moreover, pharmacists could play a positive role in conveying appropriate measures and a better code of behaviour to be adopted for preventing wide spread of the virus in upcoming years. Therefore, this study was designed with a structured questionnaire for obtaining knowledge and practices of the respondents regarding swine flu among final year students $(\mathrm{N}=100)$ of Pharmacy. Data was analyzed by MS Excel and SPSS. Over all, the students presented fair knowledge in areas of general perceptions, viral transmittance from swine and pork products, transmittance of virus among human, high risk population as compared to knowledge about duration of infection and treatment options of anti virals and vaccines. They also seemed to be well aware of the mode of spread of disease and the appropriate preventive measures.
\end{abstract}

Keywords: Swine flu; General perceptions and awareness; Role of pharmacists; Preventive strategies

\section{Introduction}

The wave of the pandemic disease world wide-Influenza Type A (H1N1) [1] has struck hard Pakistan this year creating a feared epidemic. Since the first case reported in Pakistan on August 10, 2009, the number has been increasing in magnitude. In 2015 more than 10 cases were reported with 5 deaths in the federal capital and various regions of Punjab with the start of winter [2].

Although WHO reports $0.1 \%$ mortality rate [3] but still prevention seems to be the only way out due to limited resources available at all levels of Health care facilities in Pakistan.

It is in great need to take appropriate preventive measures to prevent the outbreak of disease in the upcoming years. This is only possible through proper awareness programs to facilitate people and work at individual level to restrain from the virus.

\section{History of the swine flu pandemic}

Swine origin influenza was first recognized in the border area of Mexico and United States in April 2009 [4,5].

Origin of $\mathbf{A} / \mathbf{H} 1 \mathrm{~N} 1$ virus: Swine Influenza is basically a respiratory disorder of pigs caused by Type A Influenza virus. However, animal viruses are different from Human viruses which cannot be transmitted to and between humans but a genetic recombination is likely to occur in a person suffering from Avian Influenza A Virus and a Human Influenza A virus (Figure 1). This causes a major change in Influenza A virus resulting in pandemic transmittance from person to person with no immunity against it. Swine flu Virus which was unlikely to cause infection in humans has resulted in sporadic human infection due to exposure to infected pigs with swine influenza. The current virus of the $\mathrm{H} 1 \mathrm{~N} 1$ strain has recombination of genetic material from the avian, swine and human influenza viruses [5].

Transmission of H1N1 virus to humans: Direct transmission of virus from pigs to human is rare and in our country there are no swine farms which could create a debate but it is evident that people who work with poultry and swine are at increased risk of developing the disease. Likewise swine's are considered 'haram' and eating is strictly prohibited. Although there is a perception among people that the virus can be caught from eating pork or pork products but there is no scientific evidence [6]. It is because cooking at a high temperature more than $120^{\circ} \mathrm{F}$ kills the swine flu virus as it does with other bacteria and viruses [7].

Transmission of the H1N1 virus among humans: It is transmitted in the form of droplets from person to person especially through sneezing, coughing and handshaking while suffering from the disease. It can also be transmitted by other ways through saliva, nasal secretions, feces and blood as well. Moreover, Infection may also occur through coming in contact with contaminated surfaces.

Incubation period: Like all other viruses it has also an Incubation period which has been found to be 2 to 7 days resulting in ineffective surveillance.

Common symptoms and their difference from common flu: The clinical symptoms can vary from mild to severe upper respiratory tract infections to more severe complications including Pneumonia [8]. Although, common clinical symptoms are same as found in seasonal flu, these can be distinguished from viral respiratory illness which are usually characterized by fever, cough, sore throat but with swine origin influenza a person is likely to suffer from GI upset as well presenting symptoms of vomiting and diarrhoea.

Risk factors: Young children-less than 5 years, elderly, pregnant women and others with chronic illnesses or underlying diseased

${ }^{*}$ Corresponding author: Saima Asif, Faculty of Pharmacy, Jinnah University for Women, Pakistan, Tel: 923312608480; E-mail: drsaima1981@gmail.com

Received May 10, 2016; Accepted June 17, 2016; Published June 22, 2016

Citation: Asif S, Alam T, Naveed S (2016) Interveninig Swine Flu Epidemic. J Bioequiv Availab 8: 194-196. doi:10.4172/jbb.1000293

Copyright: (c) 2016 Asif S, et al. This is an open-access article distributed under the terms of the Creative Commons Attribution License, which permits unrestricted use, distribution, and reproduction in any medium, provided the original author and source are credited. 


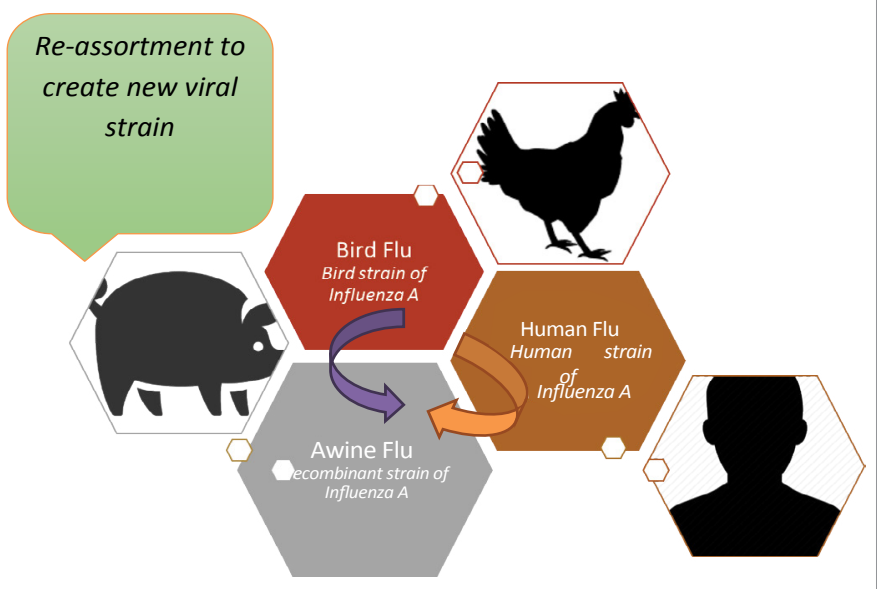

Figure 1: $\mathrm{A} / \mathrm{H} 1 \mathrm{~N} 1$ Virus. Recombination of avian, swine and human virus.

conditions have been found to be at high risk of developing the swine flu [9].

Swine origin influenza may also result in severe outcomes among which pneumonia and respiratory failure are the most common. In addition certain unusual symptoms may arise like conjunctivitis, parotitis, and hemophagocytic syndrome. Infants can be likely to present fever and lethargy with no respiratory symptoms [10].

Screening/Diagnosis: The swine influenza A (H1N1) virus infection can be confirmed by one or more of the following tests:

\section{- Real-time RT-PCR}

- Viral culture

- Quadruple increase in specific neutralizing antibodies in swine influenza A (H1N1) [11]

Treatment: The two treatment options are Vaccination and Antiviral Therapy.

Antiviral therapy: As per clinical management guidelines announced by WHO the people in groups at high risk of developing swine flu should be immediately treated with Anti-viral.

The commonly used antiviral drugs which have been found to be effective in the H1N1 virus infection include: oseltamivir and zamanavir [12] with recommended schedule of 5 days. But there is also a possibility of increasing resistance to the drug [13].

Vaccination: Vaccination are available for $\mathrm{H} 1 \mathrm{~N} 1$ virus and has been recommended by many government authorities but still there is a concern among all levels of individuals regarding their safety and efficacy $[14,15]$. There is also a shortage of resources to provide the vaccination to desired patients [13]. In such circumstances, good control practices and preventive measures taken at individual level seems to be the only way out.

Control and prevention: So far preventive measures along with individual awareness have been considered as the most appropriate way to prevent the spread of deadly virus [16]. Control and prevention can be done at two basic levels. Firstly, Swine influenza can be managed through proper herd management and vaccination. This can widely contribute to transmission of virus from swine to humans. Secondly, the measures need to be taken at personal levels (Figure 2) through proper hygiene, effective preventive tips and treatment strategies [7].

\section{Materials and Methods}

A structured questionnaire was used for obtaining knowledge and awareness regarding preventive measures among 100 students of Final year pharmacy regarding swine flu. The questionnaire comprised of different questions related to the viral disorder which included the following information:

- General perception of students about Swine flu-whether it is a respiratory disorder or a viral disease or seasonal Influenza?

- Is it transmitted from pigs?

- If it is transmitted through eating pork products?

- It was also enquired if they were aware of the population which is at increased risk of getting the infection which include infants, elderly and pregnant women?

- Its signs and symptoms observed commonly?

- The symptoms differentiating it from common influenza?

- The questionnaire also included the different treatment options available-medications?

- Vaccines available?

- Queries regarding appropriate preventive measures like washing hands frequently to prevent the spread of disease?

- Covering mouth on sneezing and coughing to prevent spread of disease and avoiding crowd's places?

\section{Results}

Study population consisted of 100 pharmacy students of Final year. The data in Table 1 presents the major statistical outcomes. Out of 100 respondents $87 \%$ had general perception about the swine flu virus but $13 \%$ did not have a fair idea about the virus with chi square value of $0<0.05$ indicating a significant difference among their knowledge. Just

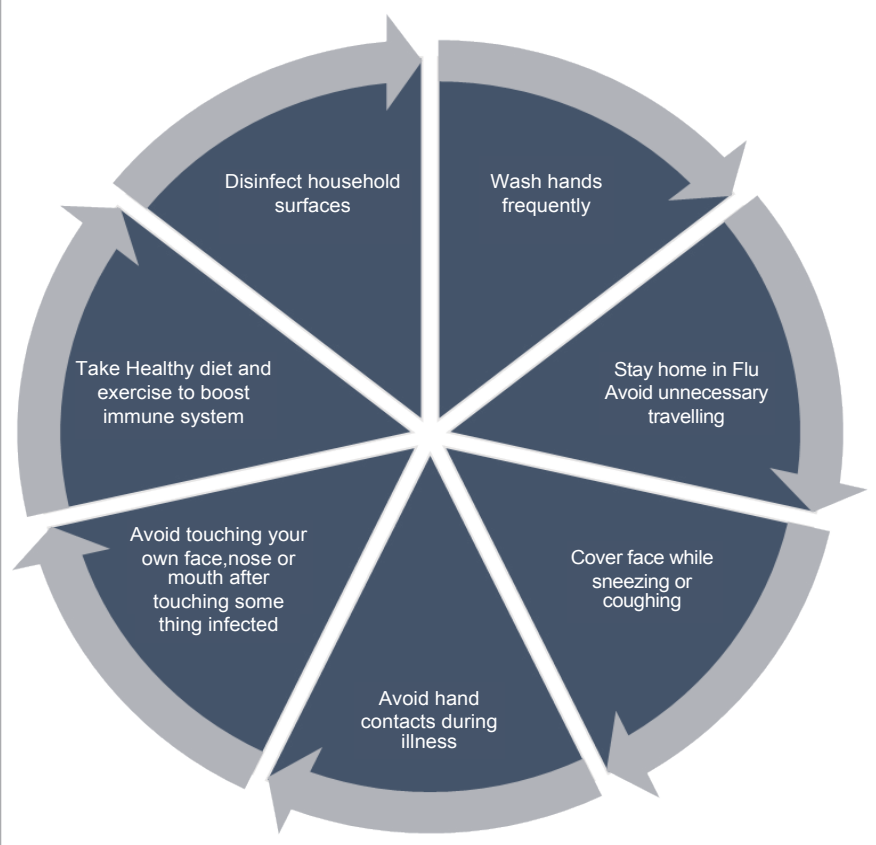

Figure 2: Effective preventive measures. 


\begin{tabular}{|l|c|c|c|c|}
\hline Questions & Yes & No & Chi Square value & $\begin{array}{c}\text { Total } \\
\text { N (\%) }\end{array}$ \\
\hline Swine flu perception & 87 & 13 & $0.000^{*}$ & 87 \\
\hline Transmittance from pig & 56 & 44 & 0.230 & 56 \\
\hline Transmittance pork & 55 & 45 & 0.317 & 55 \\
\hline Transmittance from human to human & 75 & 25 & $0.000^{*}$ & 75 \\
\hline High risk population & 72 & 28 & $0.000^{*}$ & 72 \\
\hline Symptoms & 49 & 51 & 0.841 & 49 \\
\hline Emergency warnings & 28 & 72 & $0.000^{*}$ & 28 \\
\hline Differential diagnosis & 63 & 37 & $0.009^{*}$ & 63 \\
\hline Duration of infection & 20 & 80 & $0.000^{*}$ & 20 \\
\hline Medications & 15 & 85 & $0.000^{*}$ & 15 \\
\hline Vaccines & 34 & 66 & $0.001^{*}$ & 34 \\
\hline Mode of spreading & 91 & 9 & $0.000^{*}$ & 91 \\
\hline Preventive measures & 81 & 19 & $0.000^{*}$ & 81 \\
\hline & Total & $\mathrm{N}=100$ & & \\
\hline
\end{tabular}

${ }^{*}$ Asterisks indicate significant differences using chi-square statistic $p<0.05$

Table 1: Observation.

\section{PARTICIPANTS AWARENESS OF SWINE FLU}

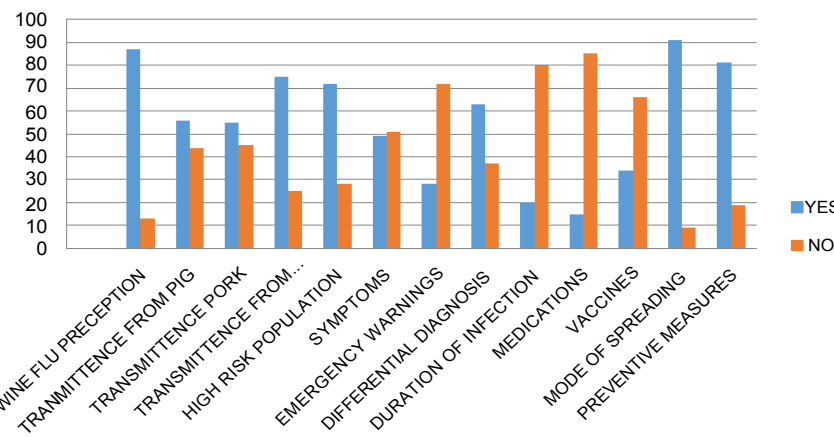

Figure 3: Participants awareness of Swine Flu.

over half of the respondents ( $56 \%$ and $55 \%$ ) believed that the virus could be transmitted from pigs and by eating pork products respectively. The chi square value of 0.230 and 0.317 respectively at this level present a non-significant difference. Another area of significant consideration was the differential diagnosis of swine flu, a significant value of 0.009 was also observed in it with $63 \%$ respondents replying in yes and the remaining replied as no. However, three fourth of the individuals (75\%) were aware about their transmittance among human through human contact. The chi square value of $0<0.05$ indicates a significant difference among their knowledge in this regards. A similar trend was observed in their awareness about the individual population which is more prone to the viral disorder and emergency warnings accounting to (72\%).

Nearly half of them (51\%) were known to clinical sign and symptoms presenting a non-significant chi square value of 0.841 . However less than one fourth (20\% and $15 \%)$ of them were aware about the incubation period and common viral medications available for use in the treatment respectively presenting a significant difference in chi square value of $0<0.05$ which was followed by another significant chi square value of 0.01 in response to the vaccinations available for treatment. In this regards $66 \%$ of the pharmacists were aware and the rest of $34 \%$ were unaware of the vaccination options.

In the last, the questions were about the mode of spread of the virus and the possible preventive measures that could be taken for prevention. A significant difference was obtained in the knowledge among individuals. $91 \%$ and $81 \%$ of respondents answered positively with remaining $9 \%$ and $19 \%$ respectively gave negative reply.

Overall, the data of students (Figure 3) show that they had fair knowledge in areas of general perceptions, viral transmittance from swine and pork products, transmittance of virus among human, high risk population as compared to knowledge about duration of infection, emergency warnings and treatment options of anti-viral medications and vaccines available. They also seemed to be well aware of the mode of spread of disease and the appropriate preventive measures.

\section{Conclusion}

It has been concluded through this survey that appropriate awareness strategies creating public awareness with the help of pharmacists regarding the threatening virus, effective preventive measures and treatment options can be beneficial to lower the intensity of the fatal virus which is a global threat. Moreover, it is highly considerable to take into account appropriate preventive measures to control H1N1 flu pandemic as compared to other treatment options available.

\section{References}

1. Moghadami M, Afsar Kazeroni $\mathrm{P}$, Honarvar B, Ebrahimi M, Bakhtiari $\mathrm{H}$, et al. (2010) Influenza A (H1N1) virus pandemic in Fars province: a report from southern Iran, July-December 2009. Iranian Red Crescent Medical Journal 12 . 231-238.

2. http://www.dawn.com/wps/wcm/connect/dawn-content-library/dawn/news/scitech/09-swine-flu-case-detected-in-faisalabad--szh-05

3. Fitzgerald DA (2009) Human swine influenza A [H1N1]: practical advice for clinicians early in the pandemic. Paediatric Respiratory Reviews 10: 154-158.

4. Novel Swine-Origin Influenza A (H1N1) Virus Investigation Team, Dawood FS Jain S, Finelli L, Shaw MW, et al. (2009) Emergence of a novel swine-origin influenza A (H1N1) virus in humans. N Engl J Med 360: 2605-2615.

5. Schmidt S (2015) Seasonal, bird and swine flu explained. South African Pharmacist's Assistant 15: 4-5

6. Parmar S, Shah N, Kasarwala M, Virpura M, Prajapati DD, et al, (2011) A review of Swine flu. J Pharm Sci Bioscientific Res 1: 11-17.

7. Khan MZA, Gajamer VR (2015) Epidemical Disease: A Review on Swine Flu Int J Phar \& Biomedical Research 2: 11-19.

8. Gupta R, Gupta P, Gupta S (2015) Swine Flu: Quadruple reassortant" Virus IJAR 1: 159-161.

9. Singh MK, Kumar P, Rajesh Kumar, Shikha Gupta, Prabhat Agrawal (2016) Clinical Profile of Swine Flu in Children at a tertiary care center. Annals of Applied Bio-Sciences 3: A75-A78.

10. Sebastian MR, Lodha R, Kabra SK (2009) Swine origin influenza (swine flu). Indian J Pediatr 76: 833-841.

11. Organization WH (2009) Interim WHO guidance for the surveillance of human infection with swine influenza $A(\mathrm{H} 1 \mathrm{~N} 1)$ virus.

12. Zarocostas J (2009) WHO recommends early antiviral treatment for at risk groups with suspected swine flu. BMJ 339: b4831.

13. Lankarani K (2010) Hajj and Swine Flu Pandemic (H1N1, 2009): What Is Expected and What Should Be Done? (2015) Iranian Red Crescent Medica Journal 12: 4-6.

14. Han YK, Michie S, Potts HW, Rubin GJ (2016) Predictors of influenza vaccine uptake during the 2009/10 influenza A H1N1v ('swine flu') pandemic: Results from five national surveys in the United Kingdom. Prev Med 84: 57-61.

15. Patavegar BN, Kamble MS, Langare-Patil S (2015) Awareness and Practices Regarding Swine Flu among Interns and Nursing Staff: A Cross-Sectional Study at Tertiary Care Hospital, Pune. International Journal of Health Sciences and Research (IJHSR) 5: 1-5

16. Singh S, Kaur P, Singh G (2013) Study to assess the awareness, perception and myths regarding swine flu among educated common public in Patiala District. Int J Res Dev Health 12: 54-60. 